\title{
Microfluidics and Nanofluidics
}

\author{
Ruey-Jen Yang \\ Department of Engineering Science, National Cheng Kung University, Tainan 701, Taiwan; \\ rjyang@mail.ncku.edu.tw
}

Received: 22 January 2019; Accepted: 2 February 2019; Published: 11 February 2019

Microfluidics and nanofluidics deal with fluid flows in geometries of micro/nano scales. New phenomena unique to these small scales have brought exciting results over the past two decades. The practical applications of this research can be found in the analysis of analytical chemistry, chemical engineering, biomedical devices, micro-thermal technologies, etc.

In this Special Issue, we invited contributions to report the state-of-the-art developments in the fields of microfluidics and nanofluidics including, but not limited to, micromixer, micropump, droplet, biomedical microfluidic devices, manipulation of micro-molecules and biofluids, lab-on-a-chip, micro total analysis, point-of-care devices, etc. Practical devices that demonstrate capabilities to solve real-world problems are of particular interest.

This Special Issue consists of eleven articles. Two of them are review papers. The first review paper [1] provides an overview of microfabrication techniques that are relevant to both research and commercial use. A special emphasis on both the most practical and recently developed methods for microfluidic device fabrication is applied, and it leads us to specifically address laminate, molding, 3D printing, and high-resolution nanofabrication techniques.

The second review paper [2] highlights microfluidic technology as a powerful tool in medical and biological research. This paper focusses on the use of microfluidics for cell cultures that has attracted much interest from scientists worldwide these days.

The third paper [3] proposes an integrated system consisting of a paper-based chip and a smart detection device for determining the human serum creatinine concentration based on Jaffé reaction theory. This paper demonstrates a practical point-of-care real-world device.

The fourth paper [4] utilizes computational fluid dynamics (CFD) method to study Taylor segments. Dense carbon dioxide $\left(\mathrm{CO}_{2}\right)$ and water are applied and used as a fluid pair. One single flowing liquid or supercritical $\mathrm{CO}_{2}$ drop enclosed by water is traced in fixed frames of a long straight microchannel.

The fifth paper [5] develops a droplet encapsulation using Dean flow in a spiral microfluidic device to separate microalgae. The microfluidic chip is a combination of two distinct designs-a spiral microchannel design to separate microalgae of various sizes, and a microdroplet generation design for cell encapsulation. The yield of the separation is enhanced through the concept of dominant forces (Dean drag force and lift force) in a spiral microchannel design, together with a design of the microdroplet generation that narrows the volume to facilitate cell observation.

The sixth paper [6] exploits electrowetting-on-dielectric (EWOD) as an actuating force to manipulate liquids by surface tension and modulation of the contact angle on a microscale. The authors developed a non-optical method to study EWOD using a quartz-crystal microbalance (QCM).

In the seventh paper [7], the authors verify the performance of cyclic block copolymer (CBC) created through front-end microchannel fabrication by applying hot embossing post-end sealing and bonding and using thermal fusion and ultraviolet (UV)/ozone surface-assist bonding methods.

The eighth paper [8] examines the effect of flow rate ratio (quotient of the dispersed phase flow rate over the continuous phase flow rate) on a regime transition from squeezing to dripping at constant capillary numbers. The effect of the flow rate ratio on the volume of droplets generated in a microfluidic T-junction is discussed, and a new scaling law to estimate their volume is proposed. 
The ninth paper [9] presents a microinjection system for gene delivery to a planarian with materials widely used by manufacturers. The system consists of a nanoliter droplet generator/injector and a planarian holder. Glass capillary needles are used to consistently generate droplets and to inject droplets into a planarian.

The tenth paper [10] proposes the use of a chip-based microfluidic device to extract functional and chemical free mitochondria. An osteosarcoma cybrid cell line is employed to demonstrate the efficiency of the proposed microfluidic device. The membrane proteins (mitochondrial complex I-V and Tom20) and morphology of the extracted mitochondria are examined by Western blot and transmission electron microscopy (TEM), respectively.

The eleventh paper [11] develops a microfluidic cell stretch device to investigate the effects of stretching stress on pulmonary artery smooth muscle cell (PASMC) proliferation in pulmonary arterial hypertension (PAH). The results are consistent with the abnormal proliferation observed in PAH, showing patient cells increased in number by stretching stress, i.e., the stretch stress itself promotes cell proliferation in PAH.

This guest editor would like to thank all contributors and the special assistance provided by Quella Zou of MDPI to make this Special Issue possible.

\section{References}

1. Gale, B.K.; Jafek, A.R.; Lambert, C.J.; Goenner, B.L.; Moghimifam, H.; Nze, U.C.; Kamarapu, S.K. A Review of Current Methods in Microfluidic Device Fabrication and Future Commercialization Prospects. Inventions 2018, 3, 60. [CrossRef]

2. Torino, S.; Corrado, B.; Iodice, M.; Coppola, G. PDMS-Based Microfluidic Devices for Cell Culture. Inventions 2018, 3, 65. [CrossRef]

3. Fu, L.-M.; Tseng, C.-C.; Ju, W.-J.; Yang, R.-J. Rapid Paper-Based System for Human Serum Creatinine Detection. Inventions 2018, 3, 34. [CrossRef]

4. Qin, N.; Feng, Y.; Wen, J.Z.; Ren, C.L. Numerical Study on Single Flowing Liquid and Supercritical $\mathrm{CO}_{2} \mathrm{Drop}$ in Microchannel: Thin Film, Flow Fields, and Interfacial Profile. Inventions 2018, 3, 35. [CrossRef]

5. Lee, M.-L.; Yao, D.-J. The Separation of Microalgae Using Dean Flow in a Spiral Microfluidic Device. Inventions 2018, 3, 40. [CrossRef]

6. Lin, J.-W.; Wang, D.-S.; Fan, S.-K. Adjustment and Measurement of Contact Angle with Electrowetting on a Quartz-Crystal Microbalance. Inventions 2018, 3, 46. [CrossRef]

7. Yen, C.-Y.; Chang, M.-C.O.; Shih, Z.-F.; Lien, Y.-H.; Tsao, C.-W. Cyclic Block Copolymer Microchannel Fabrication and Sealing for Microfluidics Applications. Inventions 2018, 3, 49. [CrossRef]

8. Loizou, K.; Wong, V.-L.; Hewakandamby, B. Examining the Effect of Flow Rate Ratio on Droplet Generation and Regime Transition in a Microfluidic T-Junction at Constant Capillary Numbers. Inventions 2018, 3, 54. [CrossRef]

9. Lee, M.; Syu, J.-J.; Chu, C.-Y.; Lu, Y.-W. Gene Delivery System Using Droplet Injector and TemperatureControlled Planarian Holder. Inventions 2018, 3, 57. [CrossRef]

10. Hsiao, Y.-H.; Li, C.-W.; Chang, J.-C.; Chen, S.-T.; Liu, C.-S.; Wang, G.-J. Chemical-Free Extraction of Functional Mitochondria Using a Microfluidic Device. Inventions 2018, 3, 68. [CrossRef]

11. Sato, K.; Nitta, M.; Ogawa, A. A Microfluidic Cell Stretch Device to Investigate the Effects of Stretching Stress on Artery Smooth Muscle Cell Proliferation in Pulmonary Arterial Hypertension. Inventions 2019, 4, 1. [CrossRef]

(C) 2019 by the author. Licensee MDPI, Basel, Switzerland. This article is an open access article distributed under the terms and conditions of the Creative Commons Attribution (CC BY) license (http://creativecommons.org/licenses/by/4.0/). 